Revue

Revue de l'histoire des religions

de Ihistoire des religions

4 | 2012

Varia

\title{
Louis GIRARD, Lamennais ou le devoir de croire
}

Hildesheim, Olms (« Europaea memoria », 74), 2010, 476 p., $24 \mathrm{~cm}, 68 €$, ISBN 978-3-487-14294-4.

\section{Elsa Deleage}

\section{OpenEdition}

Journals

Édition électronique

URL : http://journals.openedition.org/rhr/8019

DOI : 10.4000/rhr.8019

ISSN : 2105-2573

Éditeur

Armand Colin

Édition imprimée

Date de publication : 1 décembre 2012

Pagination : 562-563

ISBN : 978-2200-92796-7

ISSN : 0035-1423

\section{Référence électronique}

Elsa Deleage, "Louis GIRARD, Lamennais ou le devoir de croire », Revue de l'histoire des religions [En ligne] 4 | 2012, mis en ligne le 24 janvier 2013, consulté le 22 septembre 2020. URL : http:// journals.openedition.org/rhr/8019; DOI : https://doi.org/10.4000/rhr.8019

Ce document a été généré automatiquement le 22 septembre 2020.

Tous droits réservés 


\section{Louis GIRARD, Lamennais ou le devoir de croire}

Hildesheim, Olms (« Europaea memoria », 74), 2010, 476 p., $24 \mathrm{~cm}, 68 €$, ISBN 978-3-487-14294-4.

\section{Elsa Deleage}

\section{RÉFÉRENCE}

Louis GIRARD, Lamennais ou le devoir de croire, Hildesheim, Olms (« Europaea memoria », 74), 2010, 476 p., 24 cm, 68 €, ISBN 978-3-487-14294-4.

Oscillant entre l'essai et la biographie, ce gros ouvrage guide le lecteur dans les pas de ce prêtre singulier ayant vécu le passage de la Révolution française à l'instauration du Second Empire. Si l'on peut rappeler les travaux de Frédéric Lambert (1997), et d'Anne Philibert (2007, qui ne traite que des rapports entre Lacordaire et Lamennais), à ce jour, aucun travail de cette ampleur n'a été publié sur Lamennais. Pour préciser son analyse des écrits de Lamennais et permettre un dialogue entre divers points de vue, Louis Girard (L.G.) aurait pu ajouter à ses références Paul Janet (La philosophie de Lamennais, 1890)et René Bréhat (Lamennais ou le prophète FELI, 1966). Malgré des lacunes et l'absence de bibliographie finale, par son approche globale, cet ouvrage trouve sa place dans la bibliographie sur Lamennais. L.G. ne s'est pas limité à l'analyse de ses écrits mais a également étudié les cercles dans lesquels il évolue : La Chênaie, les Ultramontains, les Républicains, Chateaubriand, Georges Sand, Madame Yéméniz, etc. Une attention particulière est apportée à la "conversion » (ou " reconversion ») de Lamennais à travers ses écrits. Après une rapide présentation du milieu social et politique dans lequel Lamennais voit le jour, L.G. insiste sur sa réticence à adopter une vie consacrée uniquement à Dieu, contrairement à son frère Jean-Marie. Si l'on peut distinguer deux périodes - la première débutant avec la cérémonie de diaconat du 18 février 1816, la seconde avec la condamnation de Lamennais par le Saint-Siège, concrétisée par l'encyclique Mirari Vos de Grégoire XVI, le 30 août 1832 - la vie de Lamennais n'est pas 
binaire. L'homme est aussi un sceptique: il ne cesse de questionner les régimes politiques en place, la manière d'éduquer l'homme et les droits de ce dernier, doutes qui aboutiront certes à une conversion mais non pas à un reniement, ni à la négation de sa propre formation. Jusqu'en 1850, alors qu'il est député, il continue de défendre l'idée d'un retour de la monarchie. Cet ouvrage permet ainsi une mise en perspective des positions actuelles du Saint-Siège. Ainsi, la Note doctrinale concernant certaines questions sur l'engagement et le comportement des catholiques dans la vie politique (Vatican, 2002) conforte et précise la théorie de Lamennais en affirmant la nécessité d'encadrer l'engagement politique des fidèles catholiques tout en en montrant les limites.

2 L'analyse par Louis Girard des écrits et de la correspondance de Lamennais déconstruit l'image traditionnelle de ce prêtre: d'abord religieux, puis humaniste, enfin homme politique avant de (re)devenir croyant. En 1817, paraît l'Essai sur l'indifférence en matière religieuse, le premier grand écrit de Lamennais érigé par la suite en étendard de l'ultramontanisme contre le gallicanisme ou toute autre doctrine perçue comme déviante par rapport au modèle du christianisme antique. Lamennais expose les raisons qui l'ont amené à être catholique, s'inscrivant dans la continuité de l'interprétation classique des Saintes Écritures et du dogme catholique traditionaliste. Son œuvre est reçue avec un enthousiasme qui sera ensuite partagé par l'Action française. Tout en le replaçant dans une perspective philosophique générale, L.G. met très clairement en évidence les limites de l'Essai qui privilégie l'argument d'autorité et la rhétorique plutôt que la dialectique. En 1826, dans De la religion considérée dans ses rapports avec l'ordre politique et civil, Lamennais défend la monarchie absolue, avec une subordination du roi au pape, maintenant ainsi la position défendue lors de deux affaires précédentes, l'affaire dite " de la procession » et celle dite de " la sépulture des suicidés ». En outre, en 1825, en désaccord avec le régime politique en place, il revendique le retour à la monarchie et attaque le régime démocratique comme étant synonyme d'athéisme. De même, répondant à Frayssinous qui appelle "parti-prêtre " le courant ultramontain, Lamennais voit dans le gallicanisme un moyen mis en œuvre par le pouvoir politique pour domestiquer la religion catholique. Mais quand apparait progressivement la question des droits fondamentaux, les rapports entre le Saint-Siège et Lamennais changent et le font basculer dans l'autre camp de l'échiquier politique, basculement officialisé par sa publication de février 1829: Des progrès de la Révolution et de la guerre contre l'Église. Désormais, l'ambivalence de cette vie et de cette œuvre originale se retrouve dans l'accueil favorable que lui réservent des mouvements aussi différents que l'Action française et le Sillon.

\section{AUTEURS}

\section{ELSA DELEAGE}

Université Sorbonne Nouvelle - Paris III. 